\title{
PERSEPSI KONSUMEN DAN KEPUTUSAN PEMBELIAN TERHADAP PENGGUNAAN BIO-PLASTIC (Suatu Kasus pada Kini\&Nanti Kopi, Jakarta Selatan)
}

\section{CONSUMER PERCEPTION AND PURCHASE DECISION OF USE OF BIO-PLASTIC (A Case in Kini\&Nanti Kopi, South Jakarta)}

\author{
Febhy Anjani Poetri*", Trisna Insan Noor ${ }^{2}$ \\ 1,2Program Studi Agribisnis, Fakultas Pertanian, Universitas Padjadjaran \\ Jl. Raya Jatinangor Sumedang Km. 21 \\ *Email: febhy.anjani@yahoo.com \\ (Diterima 12-01-2020; Disetujui 20-01-2020)
}

\begin{abstract}
ABSTRAK
Sampah plastik telah menjadi salah satu penyebab permasalahan lingkungan di Indonesia. Produksi sampah plastik yang menggunakan bahan non-biodegradable setiap tahun selalu mengalami peningkatan. DKI Jakarta menjadi salah satu kota dengan produksi sampah plastik terbanyak di Indonesia. Meningkatnya kesadaran masyarakat terhadap pentingnya kelestarian lingkungan, ditandai dengan munculnya penggunaan bio-plastic sebagai upaya pengurangan sampah plastik. Berdasarkan permasalahan tersebut penelitian ini bertujuan untuk mengetahui persepsi konsumen dan keputusan pembelian terhadap penggunaan bio-plastic di Kini\&Nanti Kopi. Penelitian ini menggunakan desain penelitian kuantitatif dan metode survei dengan menggunakan kuisioner sebagai alat bantu dalam melakukan wawancara. Analisis yang digunakan pada penelitian ini adalah uji validitas, uji reliabilitas, analisis statistik deskriptif, analisis faktor dan analisis korelasi rank spearman. Hasil penelitian menunjukkan bahwa faktor yang paling dominan mempengaruhi persepsi konsumen adalah kualitas, faktor yang paling dominan mempengaruhi keputusan pembelian adalah pengenalan masalah dan persepsi konsumen secara signifikan berpengaruh terhadap keputusan pembelian.
\end{abstract}

Kata kunci: Bio-plastic, Persepsi, Keputusan pembelian

\begin{abstract}
Plastic waste has become one of the causes of environmental problems in Indonesia. The production of plastic waste that uses non-biodegradable materials every year always increases. DKI Jakarta is one of the cities with the most plastic waste production in Indonesia. Increased public awareness of the importance of environmental sustainability, marked by the emergence of the use of bio-plastic as an effort to reduce plastic waste. Based on these problems, this study aims to determine consumer perceptions and purchasing decisions on the use of bio-plastic in Kini \& Nanti Coffee. This study uses quantitative research designs and survey methods using questionnaires as an aid in conducting interviews. The analysis used in this study is the validity test, reliability test, descriptive statistical analysis, factor analysis, and Spearman rank correlation analysis. The results showed that the most dominant factor influencing consumer perceptions was quality, the most dominant factor influencing purchase decisions was problem recognition and consumer perceptions significantly affected purchasing decisions.
\end{abstract}

Keywords: Bio-plastic, Perception, Purchase decision 


\section{PENDAHULUAN}

Sampah plastik merupakan salah satu permasalahan lingkungan hidup yang dialami oleh masyarakat Indonesia. Menurut Data Asosiasi Industri Plastik Indonesia (INAPLAS) dan Badan Pusat Statistik (BPS), jumlah sampah plastik di Indonesia mencapai 64 juta ton per tahun, 5\% diantaranya merupakan sampah plastik yang dibuang ke laut (Bagus dkk., 2019). Hal ini didukung oleh hasil penelitian Jambeck et al. (2015) yang menyatakan bahwa saat ini Indonesia menduduki peringkat kedua di dunia setelah China dalam menghasilkan sampah plastik di lautan sebanyak 3,53 juta ton per tahun. Jumlah penggunaan bahan pengemas yang semakin bertambah belum dapat dipecahkan permasalahannya, hal ini dikarenakan sampah plastik memerlukan waktu yang sangat lama untuk terurai dengan sempurna. Bahan yang biasa digunakan untuk produksi plastik (umum) membutuhkan waktu sekitar 500-1.000 tahun untuk terurai dalam tanah (Nurhenu, 2003). Menurut Kementerian Lingkungan Hidup dan Kehutanan (2017), terjadi peningkatan volume sampah dari tahun ke tahun (Gambar 1).

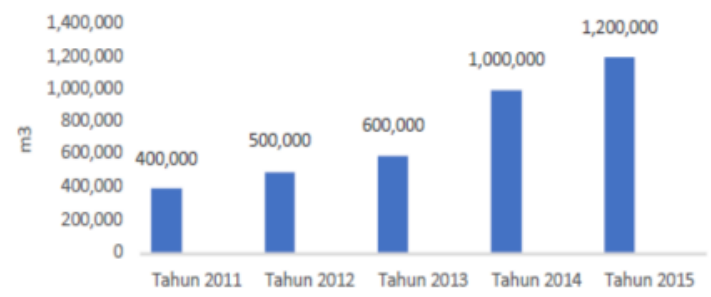

Gambar 1. Pertambahan Volume Sampah Plastik ( $\mathrm{m}^{3} /$ tahun) di 22 Kota Besar di Indonesia (Sumber: Sekretariat Adipura, KLHK 2016)

Daerah Khusus ibukota Jakarta adalah ibu kota negara dan kota terbesar di Indonesia. Saat ini volume sampah plastik di DKI Jakarta semakin bertambah, yaitu mencapai 1.000 ton. Berdasarkan data Dinas Lingkungan Hidup DKI Jakarta (2019), Plastik Sekali Pakai (PSP) menjadi penyokong kontributor cukup tinggi atas sampah plastik di DKI Jakarta yaitu sebesar $14 \%$ dari total sampah plastik 7.500 ton. Penggunaan kantong plastik yang sudah biasa di kalangan masyarakat DKI Jakarta merupakan salah satu permasalahan yang perlu diatasi. Berikut ini adalah data produksi sampah per hari menurut kota administrasi di Provinsi DKI Jakarta 2011 (Gambar 2).

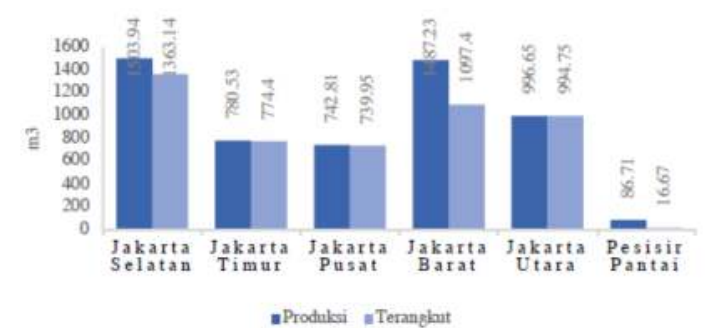

Gambar 2. Produksi Volume Sampah Yang Terangkut Per Hari (Sumber: Badan Pusat Statistika, 2011) 
Jakarta Selatan menduduki peringkat pertama terbanyak dalam volume sampah yang terangkut perharinya. Pola piker praktis, gaya hidup instan, dan tingkat kesadaran produsen ritel yang hanya memaksimalkan keuntungan menjadi bibit utama permasalahan dari pencemaran sampah plastik. Dalam keadaan seperti ini muncul yang disebut Green packaging.

Menurut Draskovic et al. (2009), Green packaging adalah salah satu dari usaha perusahaan untuk menarik minat konsumen. Saat ini salah satu penerapan dari green Packaging adalah pada pembuatan plastik dengan PLA (Jasim, 2010). Poly Latctic Acid (PLA) merupakan plastik biodegradable yang terbuat atas pati jagung, minyak nabati dan mikrobiota. Masyarakat dan para pelaku usaha telah merubah cara pandang dan pola hidupnya karena peduli dan sadar dengan keadaan lingkungan. Saat ini salah satu perusahaan di DKI Jakarta yang menerapkan green packaging sebagai strategi pemasaran hijau adalah Kini \& Nanti Kopi.

Beberapa hasil penelitian menunjukkan kesadaran konsumen terhadap produk berbasis green berpengaruh positif secara signifikan terhadap kualitas yang dirasakan dan minat beli. Hal ini membuktikan bahwa persepsi konsumen terhadap green marketing akan menjadi faktor penguat minat beli (Wu dan Chen, 2014). Lebih lanjut penelitian Santoso dan Firiyani (2016) menunjukkan green packaging, green product dan green advertising berpengaruh positif signifikan terhadap persepsi konsumen.

\begin{tabular}{lll}
\multicolumn{1}{c}{ Banyaknya } & faktor-faktor & yang \\
mempengaruhi & konsumen & dalam \\
menggunakan & bio-plastic & diduga
\end{tabular}
berhubungan dengan persepsi konsumen dan keputusan pembelian. Berdasarkan pemaparan di atas, tujuan dari penelitian ini adalah untuk mengetahui: 1) Karakteristik konsumen Kini\&Nanti Kopi; 2) Pengaruh faktor-faktor (atribut produk, kualitas, nilai, dan harga) terhadap persepsi konsumen dalam penggunaan bio-plastic; 3) Pengaruh faktor-faktor (pengenalan masalah, pencarian informasi, evaluasi alternatif, keputusan pembelian dan perilaku pasca pembelian) terhadap keputusan pembelian konsumen dalam penggunaan bio-plastic; 4) Pengaruh persepsi konsumen terhadap keputusan pembelian.

\section{METODE PENELITIAN}

Penelitian ini menggunakan pendekatan kuantitatif dengan metode survei. Objek penelitian yang diteliti 
adalah persepsi konsumen dan keputusan pembelian terhadap penggunaan bioplastic. Tempat penelitian ini berlokasi di salah satu kedai kopi di Jakarta Selatan yaitu Kini \& Nanti Kopi yang berada di Jalan Gurame Raya No.32 Pasar Minggu, Jakarta Selatan. Pemilihan lokasi ini dilakukan secara sengaja (purposive) setelah melakukan survei berdasarkan pertimbangan bahwa Kini \& Nanti Kopi merupakan kedai kopi yang menjual produknya dengan menggunakan kemasan ramah lingkungan.

Variabel yang diteliti dalam penelitian ini adalah: 1) Persepsi konsumen yang terdiri atas atribut produk, kualitas, nilai dan harga; 2) Keputusan pembelian yang terdiri atas pengenalan masalah, pencarian informasi, evaluasi alternatif, keputusan pembelian dan perilaku pasca pembelian.

Teknik pengambilan sampel dalam penelitian ini menggunakan teknik probability sampling yaitu accidental sampling. Hal ini bertujuan untuk peneliti hanya akan meneliti dan mengambil data berdasarkan responden yang datang pada saat dilakukan kegiatan penelitian secara langsung, dan memudahkan peneliti dalam memperoleh data penelitian. Populasi pada penelitian ini adalah konsumen Kini \& Nanti Kopi. jumlah sampel yang dibutuhkan untuk meneliti persepsi dan keputusan pembelian terhadap penggunaan bio-plastic di Kini\&Nanti Kopi yaitu sebanyak 77 responden.

Data dalam penelitian ini bersumber dari data primer dan data sekunder. Data primer diperoleh dari hasil observasi dan wawancara langsung terhadap responden. Data sekunder diperoleh dari sumber pustaka, seperti buku, internet, jurnal, dan lain sebagainya. Teknik pengumpulan data dilakukan melalui: 1) wawancara dengan panduan kuesioner, dan 2) pengamatan langsung (observasi) di lokasi penelitian.

Pengaruh faktor-faktor yang terdiri atas atribut produk, kualitas, nilai dan harga terhadap persepsi konsumen dalam penggunaan bio-plastic, dan pengaruh faktor-faktor yang terdiri atas pengenalan masalah, pencarian informasi, evaluasi alternatif, keputusan pembelian dan perilaku pasca pembelian terhadap keputusan pembelian dalam penggunaan bio-plastic dilakukan dengan menggunakan analisis faktor. Sedangkan untuk menganalisis pengaruh persepsi konsumen terhadap keputusan pembelian digunakan analisis korelasi rank spearman. 


\section{HASIL DAN PEMBAHASAN}

Karakteristik konsumen dijelaskan melalui karakteristik demografi yang terdiri dari jenis kelamin, usia, pendidikan terakhir, pekerjaan, dan pendapatan atau uang saku perbulan. Adapun karakteristik konsumen yang ada pada Kini\&Nanti Kopi, Jakarta Selatan tersaji pada Tabel 1.

Tabel 1. Karakteristik konsumen berdasarkan jenis kelamin

\begin{tabular}{lcc}
\hline Jenis Kelamin & $\begin{array}{c}\text { Frekuensi } \\
\text { (orang) }\end{array}$ & $\begin{array}{c}\text { Persentase } \\
(\%)\end{array}$ \\
\hline Laki-laki & 47 & 61 \\
Perempuan & 30 & 39 \\
\hline Total & 77 & 100 \\
\hline
\end{tabular}

Sumber: Hasil analisis data (2019)

Konsumen yang membeli produk kopi sebesar $61 \%$ adalah laki-laki. Hal ini menunjukkan bahwa tingkat konsumsi produk kopi didominasi dan sebagian besar merupakan aktivitas jenis kelamin laki-laki. Hal ini dikarenakan laki-laki mengkonsumsi kopi untuk membantu menyelesaikan pekerjaannya, sedangkan perempuan mengkonsumsi kopi untuk menikmati waktu santainya.

Tabel 2. Karakteristik konsumen berdasarkan usia

\begin{tabular}{ccc} 
usia & Frekuensi \\
(orang) & $\begin{array}{c}\text { Persentase } \\
(\%)\end{array}$ \\
\hline $12-16$ & 6 & 7,8 \\
$17-25$ & 43 & 55,8 \\
$26-35$ & 23 & 29,9 \\
$36-45$ & 3 & 3,9 \\
$46-55$ & 2 & 2,6 \\
\hline Total & 77 & 100 \\
\hline
\end{tabular}

Sumber: Hasil analisis data (2019)
Usia konsumen yang mengkonsumsi kopi terbanyak berkisar pada usia 17-25 tahun dengan persentase 55.8\%. Dapat disimpulkan bahwa semakin bertambah usia, tingkat keseringan konsumsi kopi semakin meningkat. Menurut Departemen Kesehatan Republik Indonesia (2009), usia 17-25 termasuk kategori remaja akhir yang tumbuh menjadi dewasa.

Tabel 3. Karakteristik konsumen berdasarkan pendidikan terakhir

\begin{tabular}{lcc}
\hline Pendidikan & $\begin{array}{c}\text { Frekuensi } \\
\text { (orang) }\end{array}$ & $\begin{array}{c}\text { Persentase } \\
(\%)\end{array}$ \\
\hline SD & 2 & 2,5 \\
SMP & 9 & 11,7 \\
SMA & 33 & 42,9 \\
Diploma & 6 & 7,8 \\
S1 & 26 & 33,8 \\
S2/S3 & 1 & 1,2 \\
\hline Total & 77 & 100 \\
\hline
\end{tabular}

Sumber: Hasil analisis data (2019)

Konsumen yang paling banyak melakukan pembelian produk kopi di Kini \& Nanti yaitu konsumen yang pendidikan terakhirnya adalah SMA yakni sebesar 42.9\%. Hal ini menunjukkan dengan pendidikan yang baik, maka pemahaman terhadap sesuatu akan lebih baik, yang nantinya akan menjadi indikator dalam perilaku mengkonsumsi. 
Tabel 4. Karakteristik konsumen berdasarkan pekerjaan

\begin{tabular}{lcc}
\hline \multicolumn{1}{c}{ Pekerjaa } & $\begin{array}{c}\text { Frekuensi } \\
\text { (orang) }\end{array}$ & $\begin{array}{c}\text { Persentase } \\
(\%)\end{array}$ \\
\hline Pelajar/Mahasiswa & 38 & 49,4 \\
Pegawai Swasta & 24 & 31,1 \\
Pegawai Negeri & & \\
Sipil & 0 & 0 \\
Ibu Rumah Tangga & 4 & 5,2 \\
Lainnya & 11 & 14,3 \\
\hline Tota & 77 & 100 \\
\hline
\end{tabular}

Sumber: Hasil analisis data (2019)

Jenis pekerjaan yang paling banyak ditekuni oleh responden Kini \& Nanti Kopi adalah Pelajar/Mahasiswa yang berjumlah 38 orang dengan persentase sebesar 49.4\%. Hal ini dapat diartikan bahwa pekerjaan dan keadaan ekonomi, pekerjaan juga mempengaruhi pola konsumsi. Semakin baik pekerjaan dan jabatan konsumen maka semakin tinggi pula pendapatannya.

Tabel 5. Karakteristik konsumen berdasarkan pendapatan atau uang saku perbulan

\begin{tabular}{ccc}
\hline $\begin{array}{c}\text { Pendapatan } \\
(000 \mathrm{Rp})\end{array}$ & $\begin{array}{c}\text { Frekuensi } \\
\text { (orang) }\end{array}$ & $\begin{array}{c}\text { Persentase } \\
(\%)\end{array}$ \\
\hline$<1.000$ & 10 & 13 \\
$1.000-3.000$ & 31 & 40,3 \\
$3.000-6.000$ & 22 & 28,5 \\
$6.000-9.000$ & 9 & 11,7 \\
$>9.000$ & 5 & 6,5 \\
\hline Tota & 77 & 100 \\
\hline
\end{tabular}

Sumber: Hasil analisis data (2019)

Kebanyakan responden memiliki pendapatan diangka $\mathrm{Rp} 1.000 .000-\mathrm{Rp}$ 3.000.000 yaitu sebanyak 31 responden atau sebesar $40.3 \%$. Dengan hasil yang didapat tersebut, didapatkan bahwa responden dengan tingkat pendapatan menengah ke bawah masih mendominasi pembelian Produk Kopi di Kini \& Nanti
Kopi, Jakarta Selatan. Hal ini berbanding lurus dengan tingkat konsumsi kopi responden yang dipengaruhi oleh tingkat harga yang ditawarkan oleh kedai kopi Kini \& Nanti yang relatif terjangkau. Dengan demikian, konsumen akan menyesuaikan kemampuan membeli dengan harga yang sesuai untuk pemilihan produk yang akan mereka beli.

Faktor-faktor yang mempengaruhi persepsi konsumen adalah atribut produk, kualitas, nilai dan harga. Dari keempat faktor tersebut yang paling dominan mempengaruhi persepsi konsumen adalah kualitas dengan nilai korelasi sebesar 0,833 (Tabel 6).

Tabel 6. Hasil Uji Component Matrix Persepsi Konsumen Component Matrix ${ }^{\mathrm{a}}$

\begin{tabular}{|l|c|}
\hline \multirow{2}{*}{} & Component \\
\cline { 2 - 2 } & 1 \\
\hline atribut & .823 \\
kualitas & .833 \\
nilai & .759 \\
harga & .554 \\
\hline
\end{tabular}

Sumber: Hasil analisis data (2019)

Menurut Adam \& Ebert (1992), postifif atau tidaknya persepsi konsumen dinilai berdasarkan baik buruknya kualitas suatu produk itu sendiri. Suatu produk dikatakan berkualitas jika memenuhi kebutuhan dan keinginan konsumen. Berdasarkan hasil penelitian, kualitas produk Kini\& Nanti Kopi ditentukan oleh konsumen dan pengalaman mereka dalam mengkonsumsi. 
Faktor kedua yang mempengaruhi persepsi konsumen adalah atribut produk dengan nilai korelasi sebesar 0,823 . Menurut Amstrong dan Kotler (2008), atribut suatu produk akan berubah-ubah sesuai dengan kepintaran produsen melihat keinginan konsumennya dan juga bisa melihat dari suatu fenomena di sekitar masyarakat. Kini \& Nanti Kopi adalah salah satu kedai kopi yang membuat inovasi terhadap atribut produknya hasil dari melihat fenomena sampah plastik.

Faktor ketiga yang mempengaruhi persepsi konsumen adalah nilai dengan nilai korelasi sebesar 0,759 . Berdasarkan penelitian ini nilai memiliki peran yang cukup penting terhadap pembentukan persepsi konsumen yang positif. Konsumen Kini\&Nanti Kopi mempercayai bahwa fungsi dari kemasan produk Kini\&Nanti terhadap lingkungan memberikan nilai atau manfaat yang sangat baik. Konsumen Kini\&Nanti Kopi mempunyai persepsi yang positif terhadap penggunaan bioplastic karena mempunyai asumsi bahwa mengkonsumsi produk Kini\&Nanti Kopi dengan kemasan yang ramah lingkungan membuatnya sadar akan lingkungan yang saat ini sedang tidak baik.

Faktor keempat yang mempengaruhi persepsi konsumen adalah harga dengan nilai korelasi sebesar 0,554. Menurut Kotrler dan Keller (2007), harga merupakan hal yang dapat dikendalikan dan menjadi faktor penentu diterima atau tidaknya suatu produk oleh konsumen. Penentuan harga tergantung pada kebijakan perusahaan tetapi tetap dengan mempertimbangkan faktor yang lain. Terjangkau atau tidaknya harga suatu produk sifatnya adalah relatif. Hal ini diperkuat dengan adanya penelitian yang dilakukan oleh Wilky Muharam (2017), hasil penelitiannya menunjukan bahwa harga memiliki pengaruh yang signifikan terhadap persepsi konsumen.

Faktor-faktor yang mempengaruhi keputusan pembelian adalah pengenalan masalah, pencarian informasi, evaluasi alternatif, keputusan pembelian dan perilaku pasca pembelian. Dari kelima faktor (sub-variabel) tersebut yang paling dominan mempengaruhi keputusan pembelian adalah pengenalan masalah dengan nilai korelasi sebesar 0,804 (Tabel 7).

Tabel 7. Hasil Rotasi Komponen Matriks Keputusan Pembelian Rotated Component Matrix ${ }^{a}$

\begin{tabular}{|l|c|c|}
\hline \multirow{2}{*}{} & \multicolumn{2}{|c|}{ Component } \\
\cline { 2 - 3 } & 1 & 2 \\
\hline Pengenalan Masalah & .077 & .804 \\
Pencarian Informasi & .604 & -.499 \\
Evaluasi Alternatif & .536 & .464 \\
Keputusan Pembelian & .632 & .052 \\
Perilaku Pasca Pembelian & .698 & .082 \\
\hline
\end{tabular}

Sumber: Hasil analisis data (2019) 
Menurut Schiffman \& Kanuk (2008), pengenalan masalah terjadi ketika konsumen menghadapi suatu masalah. Pengenalan masalah ini menjadi tahap awal dimana seseorang sadar memiliki kebutuhan dan keinginan yang harus dipenuhi. Kebutuhan tersebut dapat segera terpenuhi atau ditunda pemenuhannya tergantung dengan seberapa penting kebutuhan tersebut bagi konsumen. Jadi, berdasarkan penelitian ini didapatkan bahwa pengenalan masalah merupakan tahap proses pembelian mulai dilakukan.

Faktor kedua yang mempengaruhi keputusan pembelian adalah perilaku pasca pembelian dengan nilai korelasi sebesar 0,698. Berdasarkan penelitian yang telah dilakukan banyak sekali konsumen Kini\&Nanti Kopi yang menjadi pelanggan tetap karena pengalaman dari pembelian pertamanya. Menurut Schiffman \& Kanuk (2008), konsumen cenderung menilai pengalaman mereka ketika telah melakukan pembelian.

Faktor ketiga yang mempengaruhi keputusan pembelian adalah keputusan pembelian (sub-variabel) dengan nilai korelasi sebesar 0,632. Keputusan untuk membeli di sini merupakan proses dalam pembelian yang nyata. Situasi yang terjadi pada saat pembelian suatu produk atau jasa bisa tergantung dari sikap orang lain. Jika konsumen memutuskan untuk membeli, maka konsumen tersebut akan membuat lima sub-keputusan, yaitu: (1) Keputusan merek yang dipilih (brand decision); (2) Keputusan toko yang dipilih (vendor decision); (3) Keputusan mengenai jumlah (quantity decision); (4) Keputusan mengenai waktu pembelian (time decision); dan (5) Keputusan mengenai cara pembayaran (payment method decision).

Faktor keempat yang mempengaruhi keputusan pembelian adalah pencarian informasi dengan nilai korelasi sebesar 0,604. Berdasarkan hasil penelitian ini ternyata faktor pencarian informasi bukanlah hal yang paling mempengaruhi keputusan pembelian. Diketahui bahwa pencarian informasi dapat bersifat aktif maupun pasif. Menurut Schiffman \& Kanuk (2008), pencarian informasi secara aktif dapat berupa kunjungan langsung terhadap toko sedangkan pencarian informasi secara pasif hanya melihat atau membaca dari suatu pengiklanan. Pada proses penelitian diketahui bahwa tidak sedikit konsumen Kini\&Nanti Kopi yang melakukan kunjungan langsung ke toko karena penasaran dengan bentuk kemasan yang ramah lingkungan. Banyak dari mereka 
ketika ditanyakan darimana mengetahui kedai tersebut tidak dari teman ataupun keluarga.

Faktor kelima yang mempengaruhi keputusan pembelian adalah evaluasi alternatif dengan nilai korelasi sebesar 0,536. Faktor ini merupakan faktor terakhir yang mempengaruhi keputusan pembelian. Menurut Kotler Philip (2009), faktor ini terdiri atas dua tahap yaitu pertama menetapkan tujuan pembelian dan menilai, dan kedua mengadakan seleksi terhadap alternatif pembelian berdasarkan tujuan pembeliannya. Tujuan pembelian dari setiap konsumen Kini\&Nanti Kopi tidak selalu sama, tergantung pada jenis produk dan kebutuhannya. Kebutuhan tersebut dikelompokan menjadi tiga kategori, yaitu: 1) Konsumen yang mempunyai tujuan pembelian untuk meningkatkan gengsi; 2) Konsumen yang sekedar ingin memenuhi kebutuhan jangka pendek; 3) Konsumen yang ingin meningkatkan pengetahuan seputar bio-plastic (kemasan ramah lingkungan).

Persepsi konsumen mempunyai pengaruh positif terhadap keputusan pembelian dalam penggunaan bio-plastic. Hal ini dibuktikan dengan hasil statistik uji analisis rank spearman nilai Sig. (2tailed) $0.009<0.05$ maka ada hubungan yang signifikan (berarti) antara variabel persepsi konsumen dengan keputusan pembelian. Angka koefisien korelasi sebesar 0,298 artinya tingkat kekuatan hubungan (korelasi) antara variabel persepsi konsumen dengan keputusan pembelian adalah sebesar 0,298 atau korelasi cukup. Dengan nilai koefisien korelasi yang positif maka dapat diartikan bahwa semakin ditingkatkan persepsi konsumen maka keputusan pembelian juga akan meningkat (Tabel 8).

Hal ini sesuai dengan penelitian yang dilakukan oleh Dewi Urip (2008) dan Sofyan (1997) yang menyatakan bahwa persepsi konsumen akan berhubungan dengan perilaku seseorang dalam mengambil suatu keputusan terhadap apa yang diinginkan. Dengan memahami perilaku konsumen melalui persepsi konsumen, perusahaan ataupun pihak produsen dapat mengetahui hal-hal apa saja yang menjadi kekuatan (strength), kelemahan (weakness), peluang (opportunity) ataupun ancaman (threat) bagi produknya sendiri.

Menurut Paul dalam Urip (2008), konsumen akan menentukan pilihannya terhadap suatu produk atau jasa yang dibeli karena beberapa faktor, diantaranya adalah faktor budaya, atribut produk, kualitas dan harga produk. 
Tabel 8. Hasil Analisis Korelasi Rank Spearman

\begin{tabular}{|c|c|c|c|c|}
\hline & & & $\begin{array}{l}\text { Persepsi Konsumen } \\
\text { (X) }\end{array}$ & $\begin{array}{c}\text { Keputusan } \\
\text { Pembelian (Y) }\end{array}$ \\
\hline \multirow[t]{2}{*}{$\begin{array}{l}\text { Spearman's } \\
\text { rho }\end{array}$} & Persepsi Konsumen (X) & $\begin{array}{l}\text { Correlation } \\
\text { Coefficient } \\
\text { Sig. (2-tailed) } \\
\mathrm{N} \\
\end{array}$ & $\begin{array}{c}1.000 \\
. \\
77 \\
\end{array}$ & $\begin{array}{c}.298^{* \prime} \\
.009 \\
77 \\
\end{array}$ \\
\hline & $\begin{array}{l}\text { Keputusan Pembelian } \\
\text { (Y) }\end{array}$ & $\begin{array}{l}\text { Correlation } \\
\text { Coefficient } \\
\text { Sig. (2-tailed) } \\
\mathrm{N}\end{array}$ & $\begin{array}{c}.298^{* *} \\
.009 \\
77\end{array}$ & $\begin{array}{c}1.000 \\
77\end{array}$ \\
\hline
\end{tabular}

**. Correlation is significant at the 0.01 level (2-tailed).

Sumber: Hasil analisis data (2019)

\section{KESIMPULAN DAN SARAN}

Persepsi konsumen secara signifikan dipengaruhi oleh atribut produk, kualitas, nilai dan juga harga. Adapun faktor yang paling dominan dilihat dari nilai korelasi terbesar yaitu kualitas, dan faktor yang mempunyai pengaruh paling sedikit terhadap persepsi konsumen dengan nilai korelasi terkecil adalah harga.

Keputusan pembelian secara signifikan dipengaruhi oleh pengenalan masalah, pencarian informasi, evaluasi alternatif, keputusan pembelian dan perilaku pasca pembelian. Adapun faktor yang paling dominan dilihat dari nilai korelasi terbesar yaitu pengenalan masalah, dan faktor yang mempunyai pengaruh paling sedikit terhadap keputusan pembelian dengan nilai korelasi terkecil adalah evaluasi alternatif.

Terdapat hubungan yang signifikan antara variabel persepsi konsumen dengan keputusan pembelian dengan tingkat korelasi yang rendah. Dengan nilai koefisien korelasi yang positif maka dapat diartikan bahwa semakin ditingkatkan persepsi konsumen maka keputusan pembelian juga akan meningkat.

Kini\&Nanti Kopi perlu untuk lebih memperhatikan layanan terhadap pelanggannya, disisi itu Kini\&Nanti Kopi juga harus mampu mempertahankan atau bahkan meningkatkan kualitas dan produktivitas perusahaan, dan meninjau ulang harga yang ada pada produk Kini\&Nanti. Sehingga faktor-faktor persepsi konsumen Kini\&Nanti Kopi dalam penggunaan bio-plastic akan lebih berpengaruh dan positif. Selain itu, perusahaan dapat memproduksi varian produk yang lebih banyak lagi dan menambah jenis kemasan lainnya yang ramah lingkungan, agar dapat menarik minat beli konsumen dalam melakukan 
keputusan pembelian produk di Kini\&Nanti.

Bagi penelitian berikunya perlu menambah sub-variabel ataupun indikator yang memilki pengaruh yang terbesar bagi keputusan pembelian. Dalam penelitian ini diketahui pengaruh persepsi konsumen terhadap keputusan pembelian hanya sebesar 29,8\% oleh karena ini masih banyak faktor lain yang tidak dimasukan ke dalam model penelitian ini. Selain itu menambah jumlah sampel penelitian agar dapat menghasilkan penelitian yang lebih baik lagi.

\section{DAFTAR PUSTAKA}

Badan Pusat Statistika (BPS). 2016. Data Produksi Volume Sampah yang Terangkut PerHari. Badan Pusat Statistika. Jakarta.

Data Asosiasi Industri Plastik Indonesia (INAPLAS). 2018. Jumlah Sampah Plastik di Indonesia. Jakarta

Draskovic et al., 2009 dalam Ridwan dkk. 2018. Pengaruh Green Product, Green Advertising dan Green Brand Terhadap Keputusan Pembelian. Jurnal Ilmiah. Program Studi Ilmu Administrasi Bisnis. Fakultas Ilmu Administrasi. Universitas Brawijaya.
Jambeck, et al. 2015. Plastic waste inputs from land into the ocean. Jurnal International. UGA College of Engineering. University of Georgia Kementerian Lingkungan Hidup dan Kehutanan (KLHK). 2016. Data jumlah volume sampah di Indonesia. Kementerian Lingkungan Hidup dan Kehutanan Republik Indonesia. Jakarta.

Kementerian Perindustrian 2017. Data Asosiasi Industri Plastik Indonesia (INAPLAS). Data Jumlah Sampah Plastik Indonesia. Asosiasi Industri Plastik Indonesia. Jakarta

Santoso Imam, Fitriyani Rengganis. 2016. Green Packaging, Green Product, Green Advertising, Persepsi, dan Minat Beli Konsumen. Jurusan Teknologi Industri Pertanian. Fakultas Teknologi Pertanian Malang. Universitas Brawijaya

Wu, S. \& Chen, Y. 2015. Dampak pemasaran hijau dan persepsi inovasi pada niat pembelian untuk produk hijau. Jurnal Internasional Studi Pemasaran 